\title{
Two Examples of Award Winning Metallography
}

\author{
F.F. Noecker II \\ Department of Materials Science and Engineering, Lehigh University, 5 East Packer Ave, \\ Bethlehem PA 18015
}

Metallography is crucial in making structure property relationships, which greatly aid in formulating engineering solutions for a broad range of applications. The International Metallographic Competition (IMC), sponsored by the International Metallographic Society and Buehler, promotes outstanding metallographic practice. The goal of each IMC entry is to show how microstructural analysis played an important role in solving an engineering problem. The author won the Grand Prize at the 2002 and 2003 IMC, and was an IMC judge in 2004 and 2005. The presentation will detail the research behind the award winning posters along with tips on metallography and poster preparation.

The 2002 award winning poster was entitled Cracking Susceptibility of AISI 1013 Steel Copper Alloys. The motivation for this work was improving the thermal management of mold dies manufactured from steel alloys by selectively depositing $\mathrm{Cu}$. The thermal conductivity of $\mathrm{Cu}$ is approximately 13 times that of typical steel mold materials, however, $\mathrm{Cu}$ is a known promoter of solidification cracking in steel. Therefore, the goal of this work was to identify the range of $\mathrm{Cu}$ compositions in steel that cause cracking and understand the cracking susceptibility through analysis and modeling of microstructural development.

A wide range of Steel - $\mathrm{Cu}$ deposits, from approximately 3 to $97 \mathrm{wt} \% \mathrm{Cu}$, were fabricated using the Gas Tungsten Arc Welding (GTAW) process with cold wire feed. Initial compositional measurements were made using a rule of mixtures approach that utilized quantitative image analysis to measure the size of the weld deposit. The deposits were found to be crack free when the $\mathrm{Cu}$ concentration was above approximately $52 \mathrm{wt} \%$ or below approximately $7 \mathrm{wt} \%$. Over this span of compositions the microstructure evolved from cellular, to columnar dendritic with $\mathrm{Cu}$ enriched interdendritic regions to two types of liquid phase spinodal microstructure: one interpenetrating and the other spherical with a secondary phase separation.

At the 2003 IMC, the poster entitled Effect of Homogenization Heat Treatment on Critical Pitting Temperature and Sigma Phase Formation in Super Duplex Stainless Steel won the Grand Prize. The focus of this work was two fold: 1) to improve the critical pitting temperature (CPT) and 2) improve the resistance to sigma phase formation in super duplex stainless steel tubes that are seam welded using a laser beam welding process.

A Gleeble thermo-mechanical simulator was used to develop an optimal heat treatment schedule that could be easily implemented in a seam welded tube production line. This heat treatment increased the weldment CPT by more than $50 \%$, while decreasing sigma phase formation by $92 \%$ compared to the as-welded condition. The homogenized fusion zone microstructure was much coarser with an improved ferrite-austenite phase balance. These improvements have enabled the laser beam, seam welded tubes to effectively compete in a \$100 million annular market for long coils of super duplex stainless steel tubing. 
a)
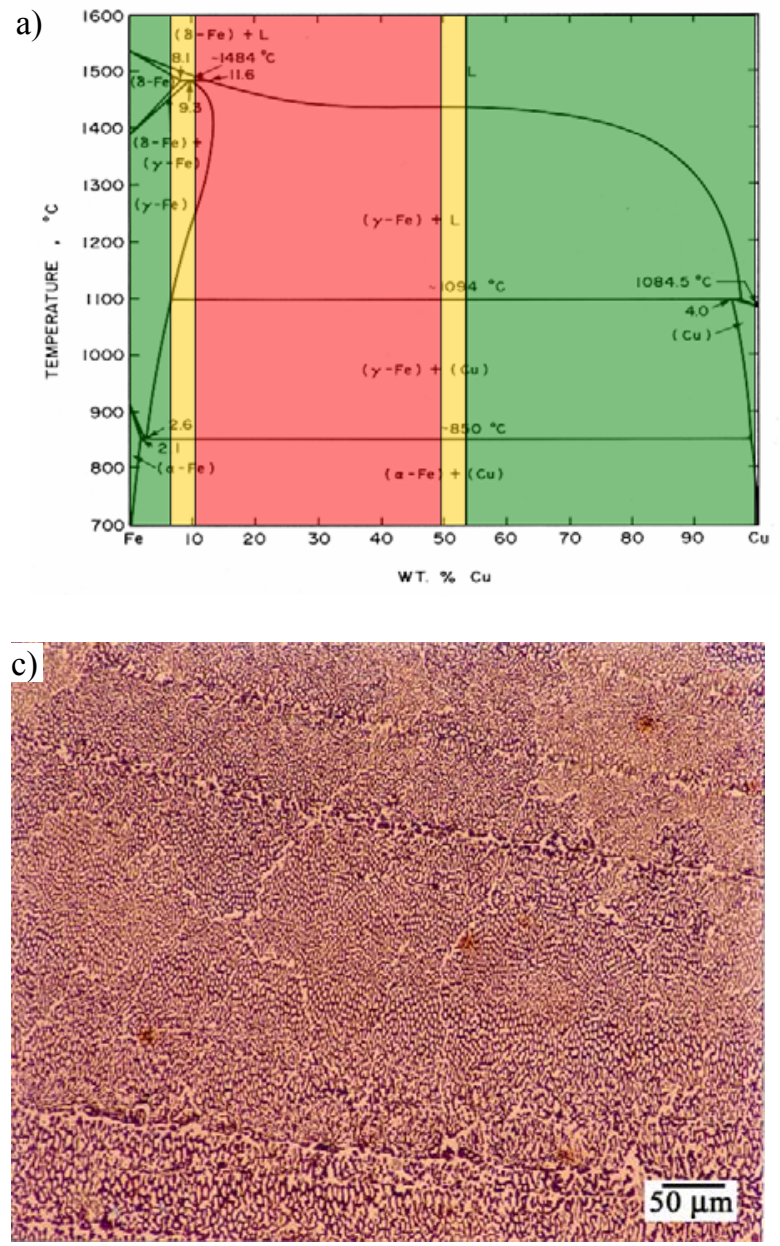
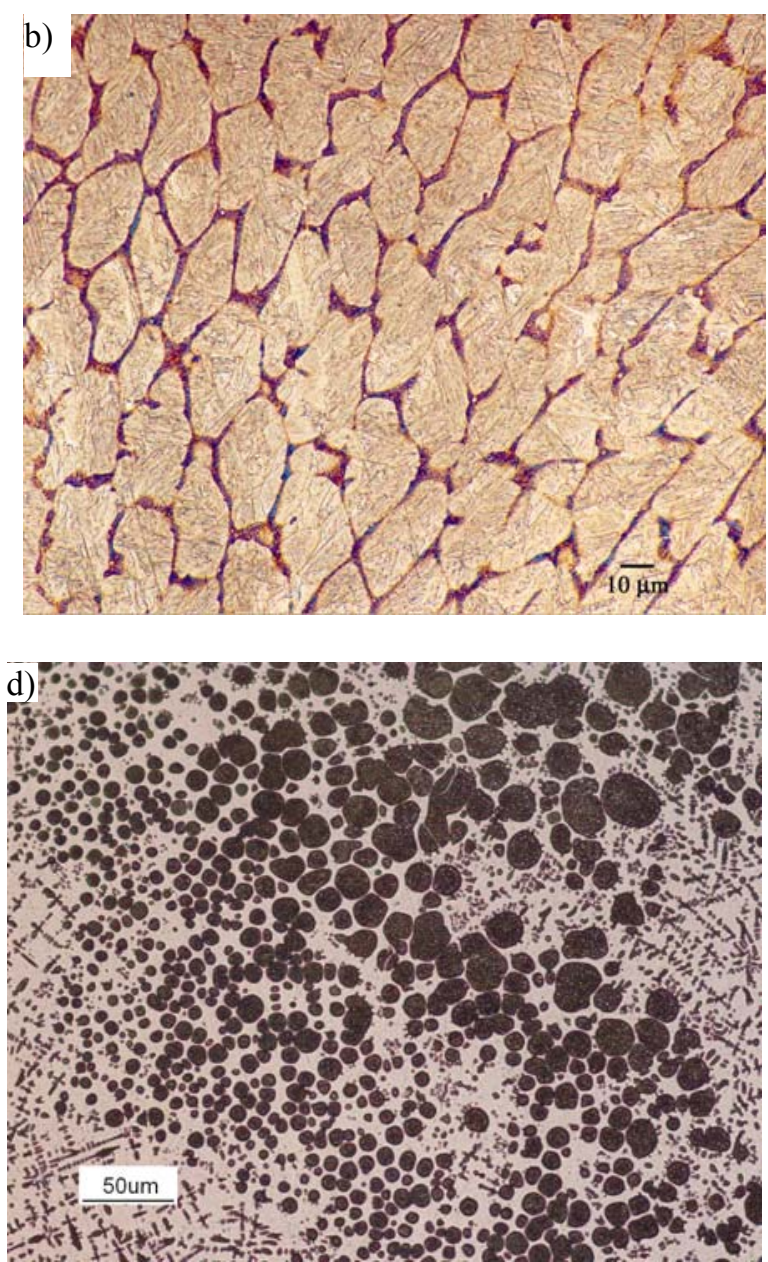

Figure 1: a) Cracking susceptibility in Steel-Cu deposit. Low (green), moderate - (yellow), high (red). Micrographs of deposits with b) 7, c) 56 and d) $61 \mathrm{wt} \% \mathrm{Cu}$.
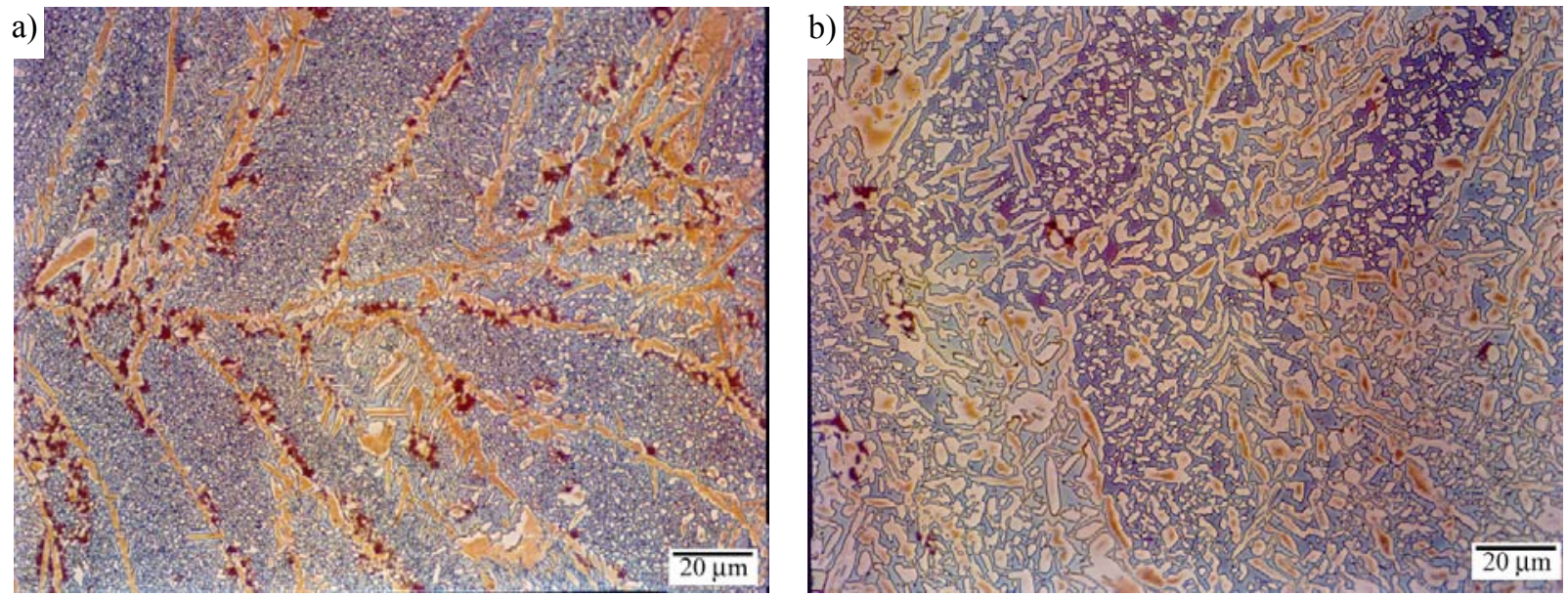

Figure 2: Centerline in fusion zone of laser beam welded super austenitic stainless steel that underwent a) a sigma forming heat treatment and b) a homogenization heat treatment followed by the same heat treatment in a). Austenite (tan), ferrite (blue) and sigma (maroon). Homogenization heat treatment decreases sigma phase formation, improves ferrite-austenite phase balance and coarsens the microstructure. 